\title{
Enhancement of LTP in Aged Rats is Dependent on Endogenous BDNF
}

\author{
Maria J Diógenes*,', Ana R Costenla', Luísa V Lopes', André Jerónimo-Santos', Vasco C Sousa', \\ Bruno M Fontinha', Joaquim A Ribeiro' and Ana M Sebastião' \\ IInstitute of Pharmacology and Neurosciences, Faculty of Medicine and Unit of Neurosciences, Institute of Molecular Medicine, University of \\ Lisbon, Lisbon, Portugal
}

\begin{abstract}
Long-term potentiation (LTP), considered the neurophysiological basis for learning and memory, is facilitated by brain-derived neurotrophic factor (BDNF), an action more evident when LTP is evoked by weak $\theta$-burst stimuli and dependent on co-activation of adenosine $A_{2 A}$ receptors $\left(A_{2 A} R\right)$, which are more expressed in aged rats. As $\theta$-burst stimuli also favor LTP in aged animals, we hypothesized that enhanced LTP in aging could be related to changes in neuromodulation by BDNF. The magnitude of CAI LTP induced by a weak $\theta$-burst stimuli delivered to the Schaffer collaterals was significantly higher in hippocampal slices taken from 36 to 38 and from 70 to 80-week-old rats, when compared with LTP magnitude in slices from 4 or 10 to 15-week-old rats; this enhancement does not impact in cognitive improvement as aged rats revealed an impairment on hippocampal-dependent learning and memory performance, as assessed by the Morris water maze tests. The scavenger for BDNF, TrkB-Fc, and the inhibitor of Trk phosphorylation, K252a, attenuated LTP in slices from 70 to 80 -week-old rats, but not from 10 to 15 -week-old rats. When exogenously added, BDNF significantly increased LTP in slices from 4 and 10 to I5-week-old rats, but did not further increased LTP in 36 to 38 or 70 to 80 -week-old rats. The effects of exogenous BDNF on LTP were prevented by the $\mathrm{A}_{2 \mathrm{~A}} \mathrm{R}$ antagonist, SCH5826I (7-(2-phenylethyl)-5-amino-2-(2-furyl)-pyrazolo-[4,3-e]I,2,4-triazolo[I,5-c]pyrimidine). These results indicate that the higher LTP magnitude observed upon aging, which does not translate into improved spatial memory performance, is a consequence of an increase in the tonic action of endogenous BDNF. Neuropsychopharmacology (20II) 36, I823-1836; doi: 10.1038/npp.201 I.64; published online 27 April 201।
\end{abstract}

Keywords: LTP; aging; BDNF; adenosine; $A_{2 A}$ receptors; hippocampus

\section{INTRODUCTION}

Long-term potentiation (LTP) is a form of synaptic plasticity widely accepted as one of the initial events required for memory encoding. Accordingly, LTP is impaired in animal models of aging associated with neurodegenerative diseases such as Alzheimer's or Huntington's diseases (Auffret et al, 2010; Rasmussen et al, 1996; Balkowiec and Katz, 2002; Rex et al, 2005; Simmons et al, 2009). However, when healthy aging is concerned, LTP is found to be impaired (Barnes, 1979; Rex et al, 2005), not altered (Costenla et al, 1999; Rex et al, 2005; Kumar et al, 2007), or even increased (Costenla et al, 1999; Kumar and Foster, 2004; Huang and Kandel, 1996). The magnitude of the deficits may depend on the synaptic circuit that is being potentiated (Rex et al, 2005) or on the used stimulation

*Correspondence: Professor MJ Diógenes, Institute of Pharmacology and Neurosciences, Faculty of Medicine and Unit of Neurosciences, Institute of Molecular Medicine, University of Lisbon, Portugal, Av. Professor Egas Moniz, Lisbon 1649-028, Portugal, Tel: + 35 121 798183, Fax: + 35 121 799 9454, E-mail: diogenes@fm.ul.pt Received 10 November 2010; revised 10 March 2011; accepted 25 March 201। pattern (Costenla et al, 1999). Thus, at a given pathway, as the CA3-CA1 synapses in the hippocampus, LTP induced by strong high-frequency stimulus is not affected by aging (Costenla et al, 1999; Rex et al, 2005), whereas LTP induced by the weaker $\theta$-burst stimulus is enhanced by aging (Costenla et al, 1999; Huang and Kandel, 1996).

Brain-derived neurotrophic factor (BDNF) is a neurotrophin that acts as a regulator of synaptic plasticity in the adult brain. It was shown that hippocampal LTP is strongly impaired in BDNF (Korte et al, 1995; Figurov et al, 1996; Patterson et al, 1996) knockout mice, a deficit that could be rescued by increasing BDNF expression (Korte et al, 1996), or even by administration of exogenous BDNF (Patterson et al, 1996). In addition, in BDNF TrkB receptor knockout mice, LTP is also severally affected (Xu et al, 2000; Minichiello et al, 2002). Moreover, upregulation of BDNF rescues synaptic plasticity deficits in an animal model of Huntington's disease (Simmons et al, 2009). These positive actions of BDNF upon synaptic plasticity, being it endogenous (Balkowiec and Katz, 2002) or exogenously added (Fontinha et al, 2008), are particularly favored in weak $\theta$-burst stimuli in the CA1-CA3 synapse. The influence of this fast-acting neurotrophin on synapses 
requires co-activation of adenosine $A_{2 A}$ receptors $\left(A_{2 A} R\right)$ (Diógenes et al, 2004; Fontinha et al, 2008; Tebano et al, 2008) and this interaction is markedly influenced by aging (Diógenes et al, 2007). Neuromodulation through $\mathrm{A}_{2 \mathrm{~A}} \mathrm{R}$ is increased upon aging (Rebola et al, 2003). Therefore, higher levels of $A_{2 A} R$ seen in aged animals facilitate synaptic effects of BDNF (Diógenes et al, 2007), in spite of lower levels of BDNF receptors in the hippocampus upon aging.

Given that (1) age-related increases in LTP induction (Kumar and Foster, 2004) are mostly evident when LTP is triggered by weak $\theta$-bust stimulus (Costenla et al, 1999), (2) this weaker pattern of LTP induction favors the facilitatory action of BDNF upon LTP (Fontinha et al, 2008), and (3) the effects of $\mathrm{BDNF}$ are potentiated or dependent on $\mathrm{A}_{2 \mathrm{~A}} \mathrm{R}$ activation (Sebastiao and Ribeiro, 2009), which are more relevant in aged subjects, we hypothesized that the enhanced LTP in aged rats could be due to an higher facilitatory influence of BDNF. To test this hypothesis, we evaluated age-related changes in magnitude of LTP induced by weak $\theta$-burst stimuli and tested the influence of endogenous and exogenously added BDNF upon LTP in hippocampal slices taken from infant (4 weeks) to aged (1.7 years) rats. In addition, we also evaluated how the effect of BDNF upon LTP in the different age groups was affected by tonic $\mathrm{A}_{2 \mathrm{~A}} \mathrm{R}$ activation, and whether the change in LTP upon aging impacts upon alteration in learning and memory.

\section{MATERIALS AND METHODS}

\section{Animals}

Experiments were performed in rat (male, Wistar, Harlan Interfauna Iberica, SL, Barcelona, Spain) hippocampi from infant rats (4 weeks old) and from three adult rat groups: young adult (10-15 weeks), age where reproductive behavior is fully established (Havenaar et al, 1993), old adult (36-38 weeks), time where rats get the third part of life expectancy (Havenaar et al, 1993), and aged rats (70-80 weeks old). Animals were handled according to European Community guidelines and Portuguese law on Animal Care and anesthetized with halothane before decapitation. Two hippocampi were isolated, one for electrophysiological recordings and the other one to evaluate BDNF immunocontent.

Ex vivo electrophysiological recordings. The hippocampus was dissected free within ice-cold Krebs' solution composed of $(\mathrm{mM}): \mathrm{NaCl} 124 ; \mathrm{KCl} 3 ; \mathrm{NaH}_{2} \mathrm{PO}_{4}$ 1.25; $\mathrm{NaHCO}_{3} 26$; $\mathrm{MgSO}_{4} 1 ; \mathrm{CaCl}_{2} 2$; and glucose 10 , previously gassed with $95 \% \mathrm{O}_{2}$ and $5 \% \mathrm{CO}_{2}, \mathrm{pH} 7.4$. Slices ( $400 \mu \mathrm{m}$ thick) were cut perpendicularly to the long axis of hippocampus with a McIlwain tissue chopper and allowed to recover functionally and energetically for $1 \mathrm{~h}$ in a resting chamber, filled with same solution, at room temperature. Slices were transferred to a recording chamber for submerged slices and continuously superfused at $3 \mathrm{ml} / \mathrm{min}$ with gassed bathing solution at $32^{\circ} \mathrm{C}$; drugs were added to this superfusion solution in an open circuit. When the effect of BDNF scavenger (Trk-Fc) was studied, slices were continuously superfused at same rate, temperature, and oxygenation, but in a closed circuit. Appropriate controls have been performed to ensure that there were no time-dependent changes in field excitatory post-synaptic potentials (fEPSPs) under either the open or the closed circuit conditions. Recordings were obtained with an Axoclamp 2B amplifier and digitized (Axon Instruments, Foster City, CA). Individual responses were monitored, and averages of eight consecutive responses continuously stored on a personal computer with the LTP software (Anderson and Collingridge, 2001).

Basal synaptic transmission. fEPSPs (Figure 1b) were recorded through an extracellular microelectrode (4M $\mathrm{NaCl}, 2-6 \mathrm{M} \Omega$ resistance) placed in stratum radiatum of CA1 area (Figure 1a). Stimulation (rectangular $0.1 \mathrm{~ms}$ pulses, once every $15 \mathrm{~s}$ ) was delivered through a concentric electrode placed on the Schaffer collateral-commissural fibers, in stratum radiatum near CA3-CA1 border (Figure 1a). The intensity of stimulus $(80-200 \mu \mathrm{A})$ was initially adjusted to obtain a large fEPSP slope with a minimum population spike contamination. Alteration in synaptic transmission induced by drugs was evaluated as the $\%$ change in the average slope of the fEPSP in relation to the average slope of the fEPSP measured during the $10 \mathrm{~min}$ that preceded the addition of drugs as described previously (Diógenes et al, 2004).

LTP induction and quantification. fEPSPs (Figure 1b) were recorded through extracellular microelectrode $(4 \mathrm{M}$ $\mathrm{NaCl}, 2-6 \mathrm{M} \Omega$ resistance) placed in stratum radiatum of CA1 area as represented in Figure 1a. In LTP experiments, stimulation (rectangular $0.1 \mathrm{~ms}$ pulses, once every $10 \mathrm{~s}$ ) was delivered alternatively to two independent pathways through bipolar concentric electrodes placed on Shaffer

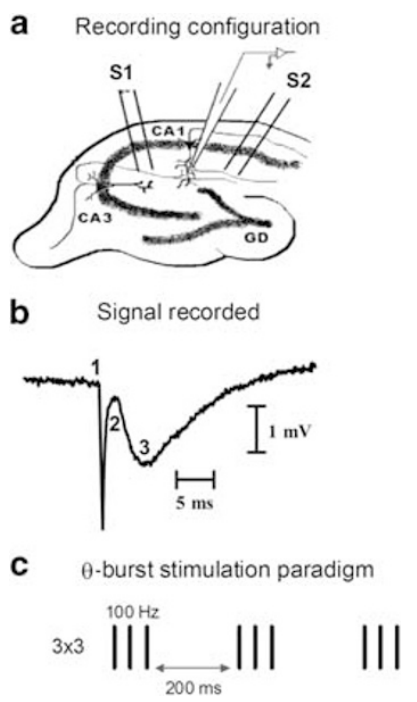

Figure I Extracellular recordings in hippocampal slices. Schematic representation of a hippocampal transverse slice preparation showing the recording configuration used to obtain extracellular responses in the CAI dendritic layer (stratum radiatum) evoked by stimulation of two (a) separate sets of the Schaffer pathway (SI and S2). (b) Examples of representative trace obtained after stimulation are composed of the stimulus artifact (I), followed by the pre-synaptic volley (2) and the field excitatory post-synaptic potentials (fEPSP) (3). A schematic representation of the stimulation paradigms used in plasticity experiments is represented in (c). 
collateral/commissural fibers in stratum radiatum (Figure 1a). LTP was induced by $\theta$-burst protocol consisting of three trains of $100 \mathrm{~Hz}$, three stimuli, separated by $200 \mathrm{~ms}$ as shown in Figure 1c.

The intensity of the stimulus was maintained during the induction protocol. LTP was quantified as the \% change in the average slope of the fEPSP taken from 46 to $60 \mathrm{~min}$ after LTP induction in relation to the average slope of the fEPSP measured during the $14 \mathrm{~min}$ that preceded the induction of LTP. In each individual experiment, the same LTP-inducing paradigm was delivered to each pathway. At $1 \mathrm{~h}$ after LTP induction in one of the pathways, BDNF $(20 \mathrm{ng} / \mathrm{ml})$ was added to the superfusion solution and LTP was induced in the second pathway, no less than $30 \mathrm{~min}$ after BDNF perfusion and only after stability of fEPSP slope values was observed for at least $10 \mathrm{~min}$. The effect of BDNF upon LTP was evaluated by comparing the magnitude of LTP in the first pathway in the absence of BDNF (control pathway), with the magnitude of LTP in the second pathway in the presence of BDNF (test pathway); each pathway was used as control or test on alternate days. To test the modification of the effect of BDNF upon LTP, the modulatory drugs were added to superfusing bath at least $30 \mathrm{~min}$ before induction of LTP in the first pathway and remained in bath up to the end of the experiment. BDNF was added, as usual, $60 \mathrm{~min}$ after the induction of LTP in the first pathway. Thus, modulatory drugs were present during both LTP-inducing periods, whereas BDNF was only present during the second induction of LTP. This protocol allows the comparison between the effect of BDNF upon LTP under different experimental conditions, keeping the magnitude of LTP under the same drug condition, without BDNF in the same slice as an internal control. When testing the effect of a drug upon LTP (rather than the modulation of the BDNF effect on LTP), the drug was added to bath $30 \mathrm{~min}$ before induction of LTP in the second pathway and the magnitude of the resulting LTP was compared with that previously obtained (first pathway) in the absence of the drug (see, Fontinha et al, 2008). In control experiments performed with hippocampal slices taken from any age group, we confirmed that when the $\theta$-burst paradigm was sequencially applied to each of the two pathways in the absence of any drug, the synaptic potentiation obtained in the first pathway was similar to that achieved in the second pathway.

Input-output curve. Input-output curves in slices from different age groups were performed to ensure that modifications in LTP magnitude were not due to changes in basal synaptic transmission. After obtaining a stable baseline for at least $15 \mathrm{~min}$, the stimulus delivered to the slice was decreased until disappearance of the fEPSPs. The stimuli delivered to the slice were successively increased by steps of $20 \mu \mathrm{A}$. For each stimulation condition, data from three consecutive averaged fEPSP (each averaged fEPSP is the computerized mean of eight individual fEPSP) were stored. The range of all inputs delivered to the slice was typically from $60 \mu \mathrm{A}$ to a supra-maximum stimulation amplitude of $300 \mu \mathrm{A}$. The input-output curve was plotted as the relationship of fEPSP slope $v s$ stimulus intensity (ie, fiber volley amplitude), which provides a measure of synaptic efficiency.

\section{Western Blotting}

Sodium dodecyl sulfate-polyacrylamide gel electrophoresis was used to evaluate levels of BDNF immunoreactivity. Hippocampi were disrupted in sucrose-Tris solution with a Teflon pestle. Proteins on hippocampal homogenate were quantified using Bio-Rad assay according to Bradford (1976). A total of $70 \mu \mathrm{g}$ of protein, for each sample, were separated on $12 \%$ polyacrylamide gels, and then transferred onto nitrocellulose membranes. After blocking with 5\% milk solution, the membranes were incubated (overnight at $4^{\circ} \mathrm{C}$ ) with primary rabbit polyclonal antibodies recognizing BDNF or $\alpha$-tubulin (Abcam), and then incubated with antirabbit secondary antibody conjugated with horseradish peroxidase for $1 \mathrm{~h}$ at room temperature. Proteins of interest were detected using ECL-Plus (Amersham Biosciences). Intensities of bands were quantified using ImageJ program. The BDNF intensity values were divided by correspondent $\alpha$-tubulin intensities (loading control).

\section{Morris Water Maze}

Young adult or aged rats (eight animals in each age group) were first habituated to handling during 5 days before testing began. The protocol used was the classical Morris water maze test, which is sensitive to hippocampaldependent spatial learning and memory (Morris et al, 1982). The maze consisted of a large circular tank $(1.8 \mathrm{~m}$ in diameter, $0.6 \mathrm{~m}$ in height) of water (temperature, $25 \pm 1^{\circ} \mathrm{C}$ ) made opaque with the addition of non-toxic water-based black paint. An escape platform $(10 \mathrm{~cm}$ in diameter) was submerged $1 \mathrm{~cm}$ below the water. Several visual cues were placed on the walls of the testing room, to be used by the animals as spatial references. An automated tracking system (Smart 2.5, PanLab, Barcelona, Spain) monitored all performances in the following parameters: swim path length; escape latency; average speed; and percentage of time spent in each quadrant. All subjects were first given a pre-training habituation session of two trials in which they were placed in the tank and allowed $60 \mathrm{~s}$ to swim to the platform located at the center of the tank. Rats were then given spatial (acquisition) training consisting of four trials per day for 5 days, in which the platform was placed at a fixed position in the center of one of the four quadrants of the tank (platform Q, left, right and across). The starting position, at which subjects were placed in the tank facing the wall, was randomly chosen across trials between four possible locations. Inter-trial interval was $15 \mathrm{~min}$, during which animals were towel-dried and placed in a heated incubator $\left(25^{\circ} \mathrm{C}\right)$ to prevent hypothermia. The maximum trial duration was $60 \mathrm{~s}$, after which animals were manually guided to the platform if they failed to locate it. Once animals reached the platform, they were allowed to remain there for $20 \mathrm{~s}$. A probe test was given after the last trial on day 5 of the acquisition. In this test, the platform was removed from the tank and animals were allowed to swim freely for $60 \mathrm{~s}$, during which the percentage of time spent on each quadrant was recorded. The results are expressed as mean \pm SEM from $n$ experiments.

\section{Drugs}

BDNF was supplied in a $1.0 \mathrm{mg} / \mathrm{ml}$ stock solution in $150 \mathrm{mM} \mathrm{NaCl}, 10 \mathrm{mM}$ sodium phosphate buffer, and $0.004 \%$ 
Tween-20, provided by Regeneron Pharmaceuticals (Tarrytown, NY). 2-[p-(2-carboxyethyl)phenethylamino]-5- $N$-ethylcarboxamido adenosine (CGS21680) was purchased from Sigma (St Louis, MO). K252-a and 7-(2-phenylethyl)5-amino-2-(2-furyl)-pyrazolo-[4,3-e]-1,2,4-triazolo[1,5-c]pyrimidine (SCH58261) were from Tocris Cookson (Ballwin, MO). The recombinant human TrkB/Fc chimera, Trk-Fc, was purchased from R\&D systems (Minneapolis, MN). CGS21680 and SCH58261 were made up in a $5 \mathrm{mM}$ stock solution in DMSO. K252-a was made in a $2.5 \mathrm{mM}$ stock solution in DMSO. TrkB-Fc was made up in a $50 \mu \mathrm{g} / \mathrm{ml}$ stock solution in PBS with $0.1 \%$ BSA. The concentration of DMSO added to slices $(0.001 \%(\mathrm{v} / \mathrm{v}))$ was below the concentration that influences glutamatergic synaptic transmission $(0.02 \%(\mathrm{v} / \mathrm{v})$;
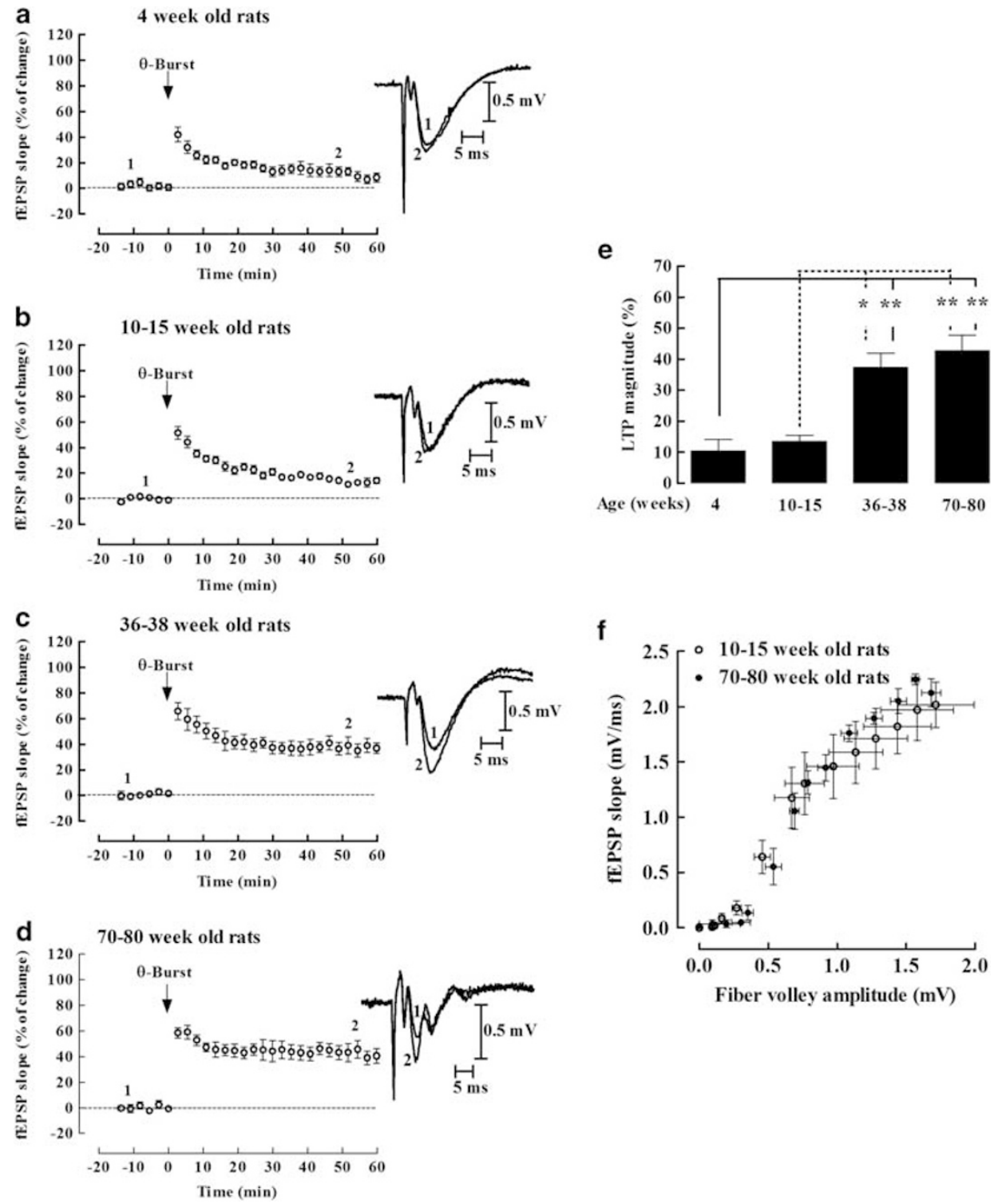

Fiber volley amplitude $(\mathrm{mV})$

Figure $2 \theta$-Burst induced long-term potentiation (LTP) but not synaptic efficiency, which is increased upon aging. Left panels in (a-d) show averaged time courses changes in field excitatory post-synaptic potential (fEPSP) slope induced by a $\theta$-burst stimulation in the absence of any drug. The ordinates represent normalized fEPSP slopes, where $0 \%$ corresponds to the averaged slopes recorded for $14 \mathrm{~min}$ before $\theta$-burst stimulation: $-0.61 \pm 0.06 \mathrm{mV} / \mathrm{ms}, n=8$ (a), $-0.58 \pm 0.06 \mathrm{mV} / \mathrm{ms}, n=7$ (b), $-0.69 \pm 0.07 \mathrm{mV} / \mathrm{ms}, n=7$ (c), and $-0.69 \pm 0.07 \mathrm{mV} / \mathrm{ms}, n=7$ (d), and the abscissa represents the time of recording. Representative traces from representative experiments are shown in the right panels in (a-d); each trace is the average of eight consecutive responses obtained before (I) and 46-60 min after (2) LTP induction, and is composed of the stimulus artifact, followed by the pre-synaptic volley and the fEPSP. Panel (e) depicts the magnitude of LTP (change in the fEPSP slope at $46-60 \mathrm{~min}$ ) induced by $\theta$-burst stimulation in relation to pre- $\theta$-burst values (0\%) in the absence of any drugs in hippocampal slices taken from the different rat ages as indicated below each column. $* P<0.0$ I and $* * P<0.00$ I (one-way analysis of variance (ANOVA) with the Bonferroni's correction). All values are mean \pm standard error of mean (SEM). In ( $f$ ) are represented input-output curves obtained in hippocampal slices of young adult rats ( $10-15$ weeks old $(O)$ ) and aged rats (70-80 weeks old $(\mathbf{O})$ ). Input-output curves are displayed as the relationship between fEPSP slope (ordinates) and stimulus intensity (measured as the amplitude of the pre-synaptic volley, in the abscissa) in the two age groups. After obtaining a stable baseline for at least $15 \mathrm{~min}$, the input delivered to the slice was decreased until the slope of the fEPSP was zero. Afterwards, the current delivered to the slice was increased by steps of $20 \mu \mathrm{A}$ at the time, with three data points collected at each stimulation amplitude (each data point being the average of eight individual fEPSP). The range of all the input delivered to the slice was typically from $60 \mu \mathrm{A}$ to a supra-maximum intensity amplitude of $300 \mu \mathrm{A}$. For each age group, the data are mean \pm SEM (both of fiber volley and fEPSP slope in each data point) of $n=3$ slices taken from different animals. 
Tsvyetlynska et al, 2005). Aliquots of stock solutions were stored at $-20^{\circ} \mathrm{C}$ until use.

\section{Data Analysis}

Values are expressed as mean \pm SEM from $n$ slices. The significance of differences between the mean values obtained in two different conditions in same slice was evaluated by the Student's $t$-test. For multiple comparisons, statistical significance was assessed by the one-way analysis of variance (ANOVA) with Bonferroni's correction. Values of $P<0.05$ were considered to represent statistically significant differences.

For results obtained in Morris water maze, a two-way ANOVA repeated measures was used to compare acquisition data from the two age groups. A Student's $t$-test was used to compare time spent in the platform quadrant between groups.

\section{RESULTS}

\section{LTP Induced by $\theta$-Burst Stimulus, but not Synaptic Efficiency, is Increased upon Aging}

The mild $\theta$-burst stimulation used in this work induced a small, but statistically significant $(P<0.05$ as compared with baseline), LTP in slices taken from 4-week-old rats $(10 \pm 3.6 \%$ increase in fEPSP slope $46-60$ min after $\theta$-burst, $n=8$; Figure $2 \mathrm{a})$ and 10 to 15 -week-old rats $(14 \pm 1.8 \%$ increase in fEPSP slope, $n=7$; Figure $2 \mathrm{~b}$ ). In contrast, in hippocampal slices taken from older rats, the same $\theta$-burst elicited a robust LTP, so that $46-60 \mathrm{~min}$ after $\theta$-burst stimulation, the fEPSP slope was increased by $35 \pm 4.6 \%$ (36 to 38 -week-old rats, $n=7$; Figure 2 c) or $43 \pm 4.9 \%$ (70 to 80 week-old rats, $n=7$; Figure 2d). As summarized in Figure 2e, LTP magnitude attained in slices from the two oldest groups was not significantly different, but it was significantly different $(P<0.01)$ from that attained in slices from younger animals ( 4 weeks or 10-15 weeks). The fEPSP recorded from slices from old animals tended to have more population spikes than in fEPSP recorded in younger animals, and this was particularly evident after LTP induction (Figure 2a-d). Indeed, a higher LTP in these slices increases the probability to detect population spike contamination. A lower GABAergic inhibition in aged rat hippocampus (Billard et al, 1995) might also contribute to higher population spikes.

To evaluate if the age-related differences in LTP magnitude could be due to changes in baseline synaptic efficiency, input-output curves in slices taken from 10 to 15 - and 70 to 80 -week-old rats were performed. Increasing stimulus intensities were delivered to the slices, as described in Materials and methods. For each intensity applied, the slope of the fEPSP (taken as a measure of the strength of the post-synaptic response) was plotted against the fiber volley amplitude (which reflects the level of pre-synaptic activation). No differences were found in input-output curves obtained in slices taken from both age groups $(n=3, P>0.05$; Figure 2f), indicating that the age-related changes in LTP cannot be accounted by differences in synaptic efficiency.
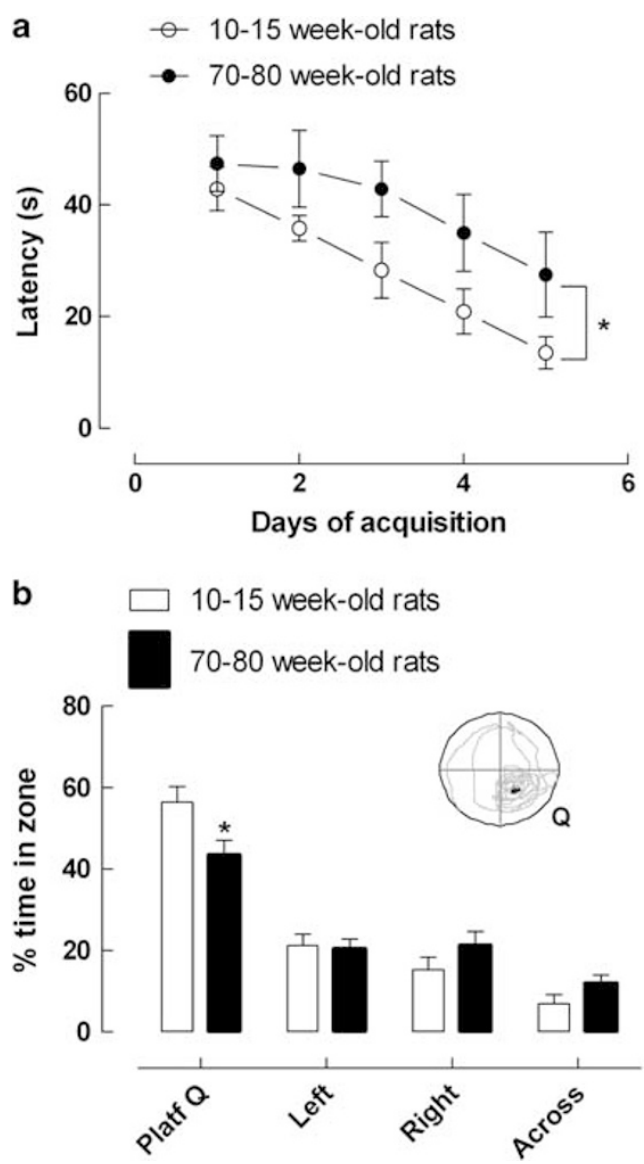

Figure 3 Comparison of the performance by young and aged rats in the spatial learning protocol of the Morris water maze. (a) Learning curve of the mean escape latencies ( \pm standard error of mean (SEM)) over the 5 days of acquisition training for young $(O)$ and aged $(0)$ animals $(n=8)$. $* P<0.01$ between the groups, two-way analysis of variance (ANOVA) repeated measures test; (b) percentage of time spent in each quadrant in hidden platform test (probe test), which was performed after the acquisition period. $* P>0.01$, Student's $t$-test.

Aged Rats Show Deficits on Hippocampal-Dependent Learning and Memory, when Compared with Young Adult Rats

To evaluate whether the increased LTP observed in aged rats was accompanied by enhanced skills at hippocampaldependent learning and memory tasks, we compared the performance of young adult (10-15 weeks old) and aged (70-80 weeks old) rats at the Morris water maze. As shown in Figure 3a, animals of both age groups improved their daily performance during acquisition phase of the Morris water maze task, but aged rats showed a much slower learning profile. ANOVA revealed significant differences in latency throughout the acquisition days $(\mathrm{F}(4.58)=29.9$, $P<0.01, n=8$; Figure $3 \mathrm{a}$ ) and an overall effect of age $(\mathrm{F}(1.58)=12.74, P<0.01, n=8)$. In probe test, both young and aged rats spent a significantly higher percentage of time in the training quadrant. However, young rats spent significantly more time $(56.5 \pm 3.7 \% n=8)$ in the training quadrant than aged rats $(43.4 \pm 3.7 \%, P<0.01$, $n=8$; Figure $3 \mathrm{~b}$ ), which indicates that aged rats have a deficient spatial memory compared with young rats. 

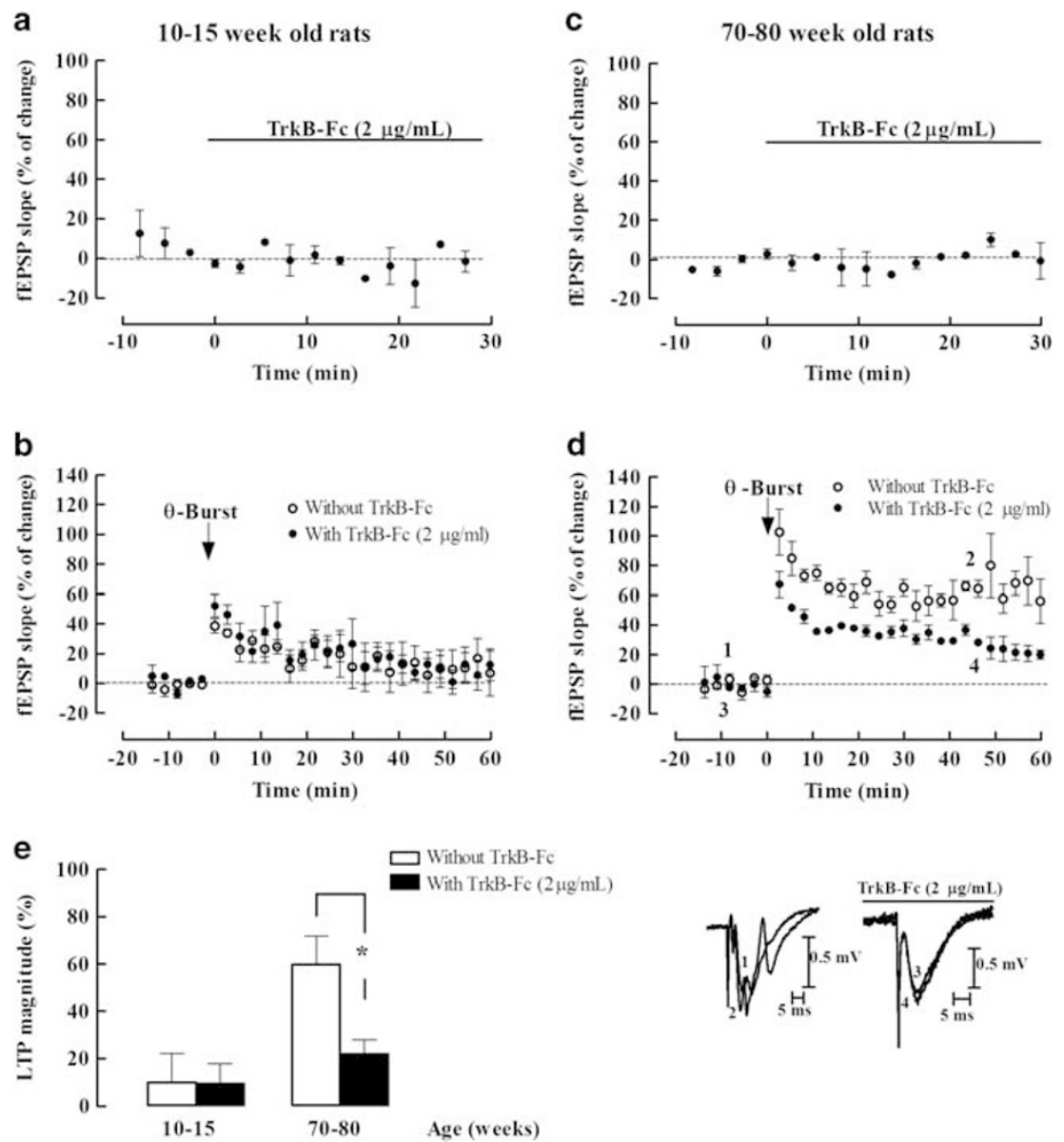

Figure 4 The brain-derived neurotrophic factor (BDNF) scavenger, TrkB-Fc, decreases the long-term potentiation (LTP) magnitude in slices taken from 70 to 80-week-old rats, but not in slices taken from 10 to 15 -week-old rats. Panels (a) and (c) illustrate virtual absence of changes in field excitatory postsynaptic potential (fEPSP) slope when TrkB-Fc $(2 \mu \mathrm{g} / \mathrm{ml}$ ) was applied to hippocampal slices taken from 10 to 15 (a) or from 70 to 80 - (c) week-old rats. Panels (b) and (d) show averaged time course changes in the fEPSP slope induced by the $\theta$-burst stimulation in the absence $(O)$ or in the presence $(\mathbf{O})$ of TrkB-Fc $(2 \mu \mathrm{g} / \mathrm{ml})$ in slices taken from 10 to 15 (b) or from 70 to 80 - (d) week-old rats. Ordinates represent normalized fEPSP slopes, where 0\% corresponds to the averaged fEPSP slopes recorded for $10 \mathrm{~min}$ immediately before TrkB-Fc, and were as follows: $-0.43 \pm 0.01 \mathrm{mV} / \mathrm{ms}(n=3, a)$ and $-0.53 \pm 0.10 \mathrm{mV} / \mathrm{ms}(n=3, c)$ or corresponds to the averaged slopes recorded for $14 \mathrm{~min}$ before $\theta$-burst stimulation: $-0.49 \pm 0.05 \mathrm{mV} / \mathrm{ms}, n=4$ (b, $-0.50 \pm 0.06 \mathrm{mV} / \mathrm{ms}, n=4(\mathrm{~b}, \bigcirc),-0.55 \pm 0.01 \mathrm{mV} / \mathrm{ms}, n=3(\mathrm{~d}, \boldsymbol{O})$, and $-0.59 \pm 0.02 \mathrm{mV} / \mathrm{ms}, n=3(\mathrm{~d}, O)$. The abscissas represent the time of every recordings. Representative traces from a representative experiment are shown below panel (d); each trace is the average of eight consecutive responses obtained before ( $\mathrm{I}$ and 3 ) and 46-60 min after (2 and 4) LTP induction, and is composed of the stimulus artifact, followed by the pre-synaptic volley and the fEPSP. Panel (e) depicts the magnitude of LTP (change in the fEPSP slope at 46-60 min) induced by $\theta$-burst stimulation in relation to pre- $\theta$-burst values (0\%) in the absence of any drugs (control) and in the presence of TrkB-Fc $(2 \mu \mathrm{g} / \mathrm{ml}$ ) in slices from 10 to 15 week and 70 to 80 -week-old rats. *P $<0.05$ (paired Student's $t$-test). All values are mean \pm standard error of mean (SEM).

The repeated measures ANOVA has revealed a consistent pattern across all the four quadrants regardless of the age factor $(P>0.05)$.

\section{In Aged Rats Tonic Influence of Endogenous BDNF upon LTP is Enhanced}

Weak $\theta$-burst stimulation favors the release of BDNF (Balkowiec and Katz, 2002; Gartner and Staiger, 2002) as well as the facilitatory action of this neurotrophin upon LTP (Fontinha et al, 2008). To investigate whether the agerelated increase in LTP magnitude could be related to a higher influence of endogenous BDNF, we evaluated the influence of BDNF's scavenger, TrkB-Fc $(2 \mu \mathrm{g} / \mathrm{ml})$, upon LTP in hippocampal slices from 10 to 15 and 70 to 80 -weekold rats. TrkB-Fc $(2 \mu \mathrm{g} / \mathrm{ml})$ was added to hippocampal slices
30 min before $\theta$-burst stimulation and remained in the bath up to the end of experiment in a close circuit as described in Materials and methods. Under these conditions and in the absence of the scavenger LTP magnitude in slices taken from young adult rats was $19 \pm 14 \%$ (Figure $4 \mathrm{~b}$ and e, $n=3$, $P<0.05$ as compared with baseline) and in slices from 70 to 80 -week-old rats it was $59 \pm 14 \%$ (Figure $4 \mathrm{~d}$ and e, $n=3$, $P<0.05$ as compared with baseline), therefore within the same values as that found in the first group of experiments (Figure 2). The scavenger was devoid of effect on hippocampal synaptic transmission in slices taken from either group of animals (Figure $4 \mathrm{a}$ and $\mathrm{c}, n=3$ ). Furthermore, TrkB-Fc $(2 \mu \mathrm{g} / \mathrm{ml})$ did not change LTP magnitude (Figure $4 \mathrm{~b}$ and e, $n=3, P>0.05$ as compared with LTP magnitude in the absence of the scavenger) in slices taken from 10 to 15-week-old rats. However, as shown in Figure 
$4 \mathrm{~d}$ and e, TrkB-Fc $(2 \mu \mathrm{g} / \mathrm{ml})$ significantly decreased $(P<0.05)$ the magnitude of LTP in slices taken from aged rats. Note, however, that under those conditions, a small but significant LTP $(22 \pm 5.5 \%, n=3, P<0.05$ as compared with baseline) still occurred in slices from aged rats, the magnitude being similar to that observed in slices from young adults (Figure $4 \mathrm{e}$ ).

To further evaluate the contribution of endogenous BDNF to $\theta$-burst-induced LTP in the two age groups (10 to 15 and 70 to 80 -week-old rats), we tested the effect of an inhibitor of Trk phosphorylation, K252a (Knusel and Hefti, 1992). K252a was used at a concentration $(200 \mathrm{nM})$ known to prevent BDNF actions on hippocampal synaptic transmission (eg, Kang and Schuman, 1995; Diógenes et al, 2004) and plasticity (Fontinha et al, 2008), without directly affecting LTP in slices from infant rats (Fontinha et al, 2008). The inhibitor of Trk phosphorylation was added to superfusing bath at least $30 \mathrm{~min}$ before induction of LTP in the second pathway, remaining in the bath up to the end of experiment, and was devoid of effect upon synaptic transmission in slices from either young adult (Figure 5a) or aged (Figure 5c) rats. Also, and in accordance with previous observations in infant rats (Fontinha et al, 2008), K252a $(200 \mathrm{nM})$ did not significantly $(P>0.05)$ affect LTP magnitude in slices taken from 10 to 15 -week-old rats (Figure $5 \mathrm{~b}$ and $\mathrm{e}$ ). In contrast, in slices taken from older (70-80 weeks) rats, K252a (200 nM) significantly decreased LTP (Figure $5 \mathrm{~d}$ and e, $n=3, P<0.05$ ), in agreement with data obtained with BDNF scavenger (Figure 4), which reinforces the conclusion that endogenous BDNF is involved in the enhancement of LTP upon aging. It is worth noting that in the absence of K252a, LTP magnitude in these experiments was statistically significant $(P<0.05)$ either in slices from young adult $(20 \pm 7.1 \%, n=3)$ or aged
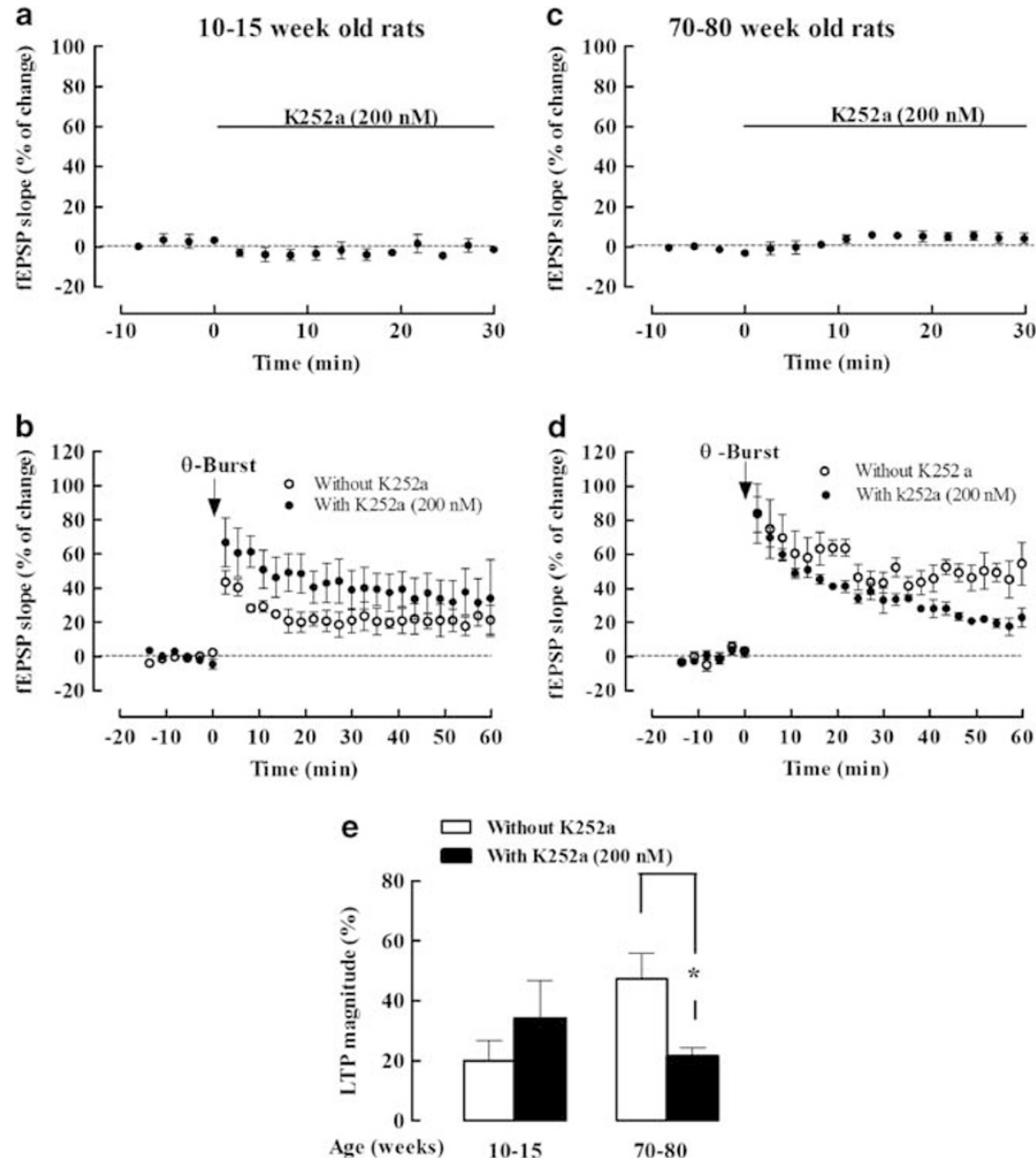

Figure 5 The inhibitor of Trk phosphorylation, K252A, decreases the long-term potentiation (LTP) magnitude in slices taken from 70 to 80 -week-old rats, but not in slices taken from 10 to 15 -week-old rats. (a) and (c) show averaged time courses changes in field excitatory post-synaptic potential (fEPSP) slope induced by K252a (200 nM) when applied to hippocampal slices taken from 10 to 15 (a) or from 70 to 80 - (c) week-old rats. (b) and (d) show averaged time courses changes in fEPSP slope induced by the $\theta$-burst stimulation in the absence $(O)$ or in the presence $(\mathbf{O})$ of $\mathrm{K} 252 \mathrm{a}(200 \mathrm{nM})$ in slices taken from 10 to 15 (b) or 70 to 80- (d) week-old rats. Ordinates represent normalized fEPSP slopes, where $0 \%$ represents the averaged fEPSP slopes recorded for $10 \mathrm{~min}$ immediately before $\mathrm{K} 252 \mathrm{a}$ administration, and were $-0.72 \pm 0.1 \mathrm{I} \mathrm{mV} / \mathrm{ms}, n=4$ (a) and $-0.72 \pm 0.07 \mathrm{mV} / \mathrm{ms}, n=4$ (c) or represent normalized fEPSP slopes, where $0 \%$ corresponds to the averaged slopes recorded for $14 \mathrm{~min}$ before $\theta$-burst stimulation: $-0.74 \pm 0.01 \mathrm{mV} / \mathrm{ms}, n=4$ (b, - ), $-0.62 \pm 0.02 \mathrm{mV} / \mathrm{ms}, n=4(\mathrm{~b}, \mathrm{O}),-0.55 \pm 0.0 \mathrm{I} \mathrm{VV} / \mathrm{ms}, n=3(\mathrm{~d}, \mathbf{O})$, and $-0.69 \pm 0.02 \mathrm{mV} / \mathrm{ms}, n=3(\mathrm{~d}, O)$. The abscissa represent the time of every recordings. Panel (e) depicts the magnitude of LTP (change in the fEPSP slope at $46-60 \mathrm{~min}$ ) induced by $\theta$-burst stimulation in relation to pre- $\theta$-burst values $(0 \%)$ in the absence of any drugs (control) and in the presence of $\mathrm{K} 252 \mathrm{a}(200 \mathrm{nM})$ in slices from 10 to 15 and 70 to 80 -week-old rats. All values are mean \pm standard error of mean (SEM). $* P<0.05$ (paired Student's $t$-test). 
a
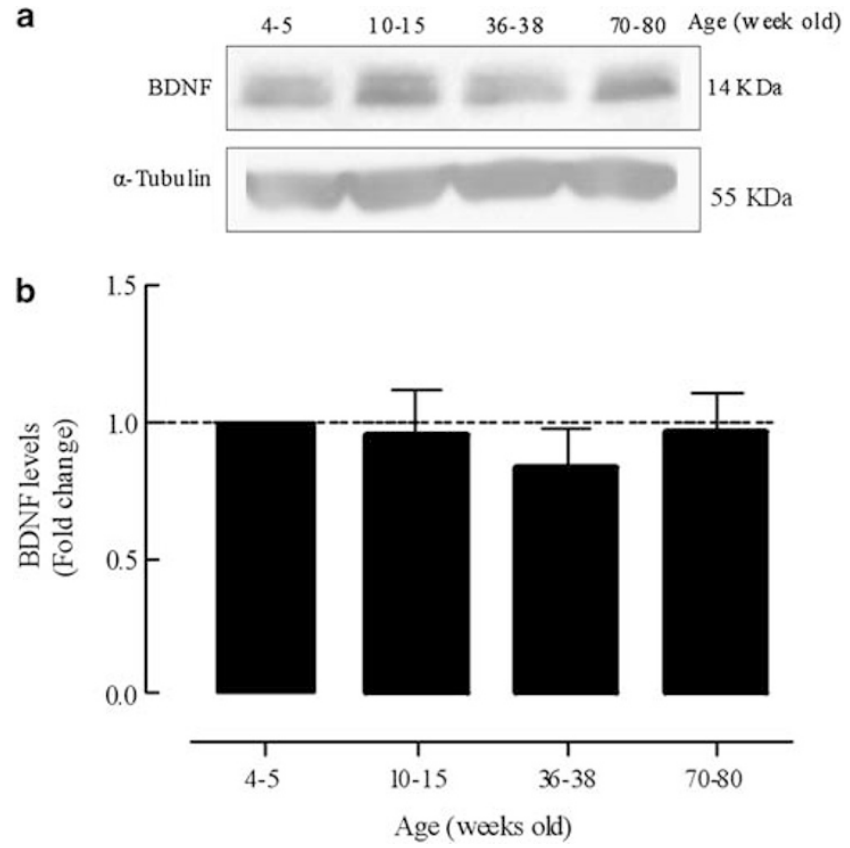

Figure 6 Levels of endogenous brain-derived neurotrophic factor (BDNF) in the different age groups. In (a) are shown the western blots of BDNF ( $14 \mathrm{kDa}$ ) and $\beta$-tubulin ( $55 \mathrm{kDa}$, loading control), in homogenates of rat hippocampus taken from 4,10 to 15,36 to 38 , and 70 to 80 -weekold rats, as indicated above each lane. In (b) are shown the averaged of BDNF levels $(n=4-5)$. All values are mean \pm standard error of mean (SEM). The levels of BDNF in infant (4 weeks old) rats were taken as I. The hippocampus homogenates were taken from the same animals that were used in electrophysiology experiments.

$(48 \pm 8.5 \%, n=3)$ rats, and that similarly to what occurred in the presence of TrkB-Fc, in the presence of $\mathrm{K} 252 \mathrm{a}$, a small but significant LTP $(21 \pm 3.0 \%, n=3, P<0.05$ as compared with baseline) was still detected in slices from aged rats (Figure $5 \mathrm{~d}$ and e).

The age-related modifications of endogenous BDNF levels might be confined to synaptic areas as no significant differences $(P>0.05, n=5)$ between BDNF immunoreactivity on hippocampal homogenates from the four age groups were detected (Figure 6).

\section{Changes in Effect of Exogenous BDNF upon LTP are Age-Related Dependent}

We next evaluated whether any effect of exogenously added BDNF upon LTP was also influenced by age. BDNF $(20 \mathrm{ng} / \mathrm{ml})$ was added to slices $60 \mathrm{~min}$ after LTP induction in first pathway and $30 \mathrm{~min}$ before LTP induction in second pathway, and remained in the bath up to the end of experiments. As illustrated in Figure 7a, in hippocampal slices from young animals (4 weeks old), BDNF caused a marked facilitation of LTP, in accordance with previous reports (Fontinha et al, 2008). In hippocampal slices taken from 10 to 15 -week-old rats, the $\theta$-burst stimulus applied in the presence of BDNF also induced a robust LTP $(33 \pm 3.2 \%$ increase in fEPSP slope, $n=5$; Figure $7 \mathrm{~b}$ ), which was significantly higher $(P<0.05$; Figure $7 e)$ than that obtained in the other pathway in the absence of BDNF $(13 \pm 1.8 \%$ increase in fEPSP slope).
In contrast, when applied to hippocampal slices taken from 36 to 38-week-old rats, BDNF did not cause a further increase in LTP (Figure 7c and e). Indeed, $\theta$-burst stimulation induced a $42 \pm 7.0 \%$ increase in fEPSP slope $(n=4)$ in the presence of BDNF and $37 \pm 7.4 \%$ increase in fEPSP slope, in the same slices without applying BDNF $(P>0.05)$. Similar results were obtained with the oldest group (70-80 weeks old) of rats, where the presence of BDNF also did not induce any further significant increase in LTP magnitude $(37 \pm 1.4$ or $35 \pm 3.5 \%$ increase in fEPSP slope $60 \mathrm{~min}$ after the $\theta$-burst in the presence or absence of BDNF, respectively, $n=4$, $P>0.05$; Figure $7 \mathrm{~d}$ and e).

It is worth noting that magnitude of LTP in slices taken from 36 to 38 or 70 to 80 -week-old rats under control conditions (no BDNF added) is similar to that observed in slices taken from 10 to 15 -week-old rats, but in the presence of BDNF.

The effect of BDNF upon LTP, whenever observed (4 weeks and 10 to 15 -week-old rats), was prevented by blockade of $\mathrm{A}_{2 \mathrm{~A}} \mathrm{R}$ with the selective $\mathrm{A}_{2 \mathrm{~A}} \mathrm{R}$ antagonist, SCH58261 (100 mM; Figure 8), which is in conformity with previously reported influence of $\mathrm{A}_{2 \mathrm{~A}} \mathrm{R}$ upon the effect of BDNF on synaptic transmission (Diógenes et al, 2004, 2007; PMID: 17421024) and LTP (Fontinha et al, 2008).

\section{Influence of $\mathrm{A}_{2 \mathrm{~A}} \mathrm{R}$ Blockade upon $\boldsymbol{\theta}$-Burst-Induced LTP is Aged-Related Dependent}

As the effect of BDNF upon LTP requires co-activation of adenosine $\mathrm{A}_{2 \mathrm{~A}} \mathrm{R}$ (Figure 8 and Fontinha et al (2008)), blockade of $\mathrm{A}_{2 \mathrm{~A}} \mathrm{R}$ should markedly reduce the magnitude of LTP in old animals if, as data with the BDNF scavenger and Trk phosphorylation inhibitor (Figures 4 and 5) suggested, the boosted LTP at these ages results from an enhanced action of endogenous BDNF upon LTP. To test directly that hypothesis, we compared the effect of the $\mathrm{A}_{2 \mathrm{~A}} \mathrm{R}$ antagonist upon LTP in hippocampal slices taken from the different age groups. SCH58261 was used at a concentration (100 nM) selective for rat $\mathrm{A}_{2 \mathrm{~A}} \mathrm{R}$ (Zocchi et al, 1996), and was added to perfusion solution $60 \mathrm{~min}$ after induction of LTP in the first pathway and at least $30 \mathrm{~min}$ before LTP induction in the second pathway. As sumarized in Figure 9, the $\mathrm{A}_{2 \mathrm{~A}} \mathrm{R}$ antagonist significantly $(P<0.05)$ reduced LTP magnitude in slices from 36 to 38 and 70 to 80 -week-old rats, but was virtually devoid of effect on LTP in slices from younger animals (4 and 10-15 weeks). Interestingly, in the presence of SCH58261 $(100 \mathrm{nM})$, LTP magnitude in aged rats $(\geqslant 36$ weeks old) was similar to that observed in younger animals either in the presence or absence of SCH58261 (Figure 9).

\section{DISCUSSION}

The main finding of this work is that the higher LTP observed after $\theta$-burst stimulation upon aging is a consequence of an increase in facilitation of LTP by endogenous BDNF. However, the increased LTP does not translate into improved spatial memory performance of the aged animals.

It is classically established that LTP in the hippocampus is a prototypical experimental model that translates into forms 
a

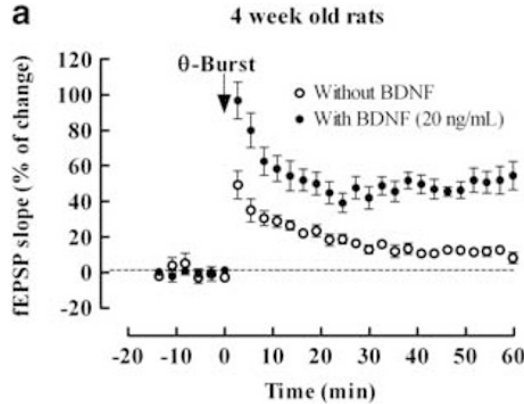

b

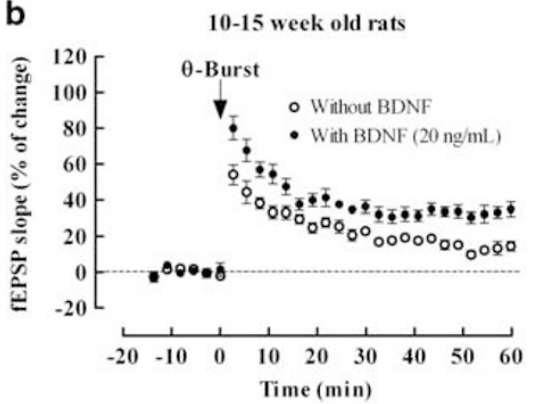

C

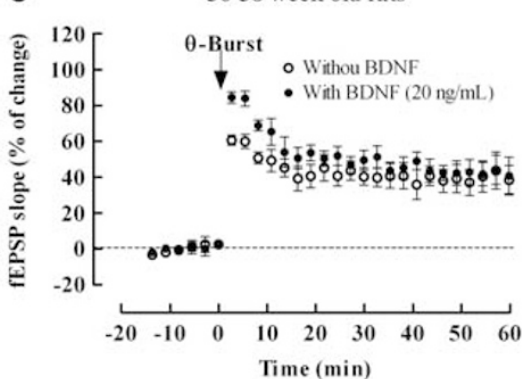

d

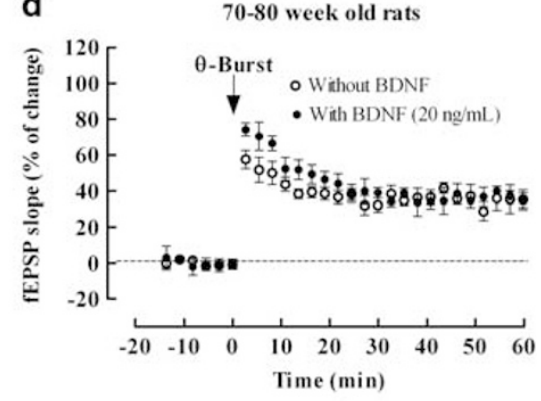

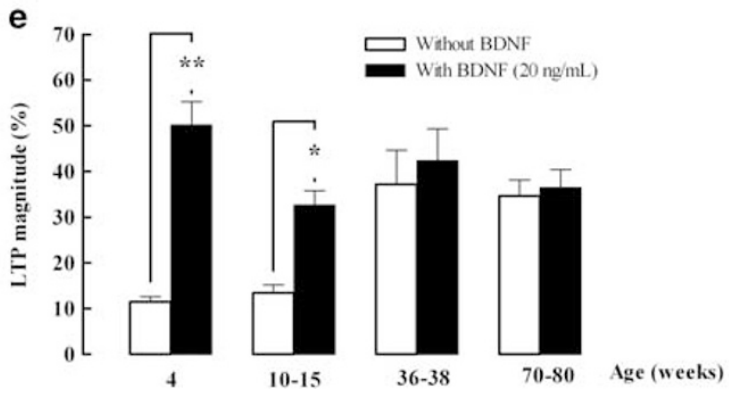

Figure 7 Age-dependent effects of brain-derived neurotrophic factor (BDNF) (20 ng/ml) on $\theta$-burst induced long-term potentiation (LTP). Panels (a)-(d) show averaged time courses changes in field excitatory post-synaptic potential (fEPSP) slope induced by the $\theta$-burst stimulation in the absence ( $O$ ) or in the presence $(\mathbf{O})$ of BDNF $(20 \mathrm{ng} / \mathrm{ml})$ in hippocampal slices taken from 4 (a), 10 to I 5 (b), 36 to 38 (c), and 70 to 80 - (d) week-old rats. BDNF (20 ng/ml) was applied $60 \mathrm{~min}$ after the induction of LTP in the first pathway $(O)$ and at least 30 min before induction of LTP in the second pathway $(0)$. The ordinates represents normalized fEPSP slopes, where $0 \%$ corresponds to the averaged slopes recorded for 14 min before $\theta$-burst stimulation: $-0.61 \pm 0.06 \mathrm{mV} / \mathrm{ms}$, $n=4(a, O),-0.52 \pm 0.06 \mathrm{mV} / \mathrm{ms}, n=4(a, \bigcirc),-0.58 \pm 0.06 \mathrm{mV} / \mathrm{ms}, n=5(b, O),-0.57 \pm 0.06 \mathrm{mV} / \mathrm{ms}, n=5(b, 0),-0.69 \pm 0.07 \mathrm{mV} / \mathrm{ms}, n=4(\mathrm{c}, O)$, $-0.68 \pm 0.05 \mathrm{mV} / \mathrm{ms}, n=4(\mathrm{c}, \mathbf{O}),-0.69 \pm 0.07 \mathrm{mV} / \mathrm{ms}, n=4(\mathrm{~d}, \mathrm{O})$, and $-0.68 \pm 0.07 \mathrm{mV} / \mathrm{ms}, n=4(\mathrm{~d}, \boldsymbol{O})$, and the abscissa represents the time of every recordings. All values are mean \pm standard error of mean (SEM). Panel (e) depicts the magnitude of LTP (change in the fEPSP slope at 46-60 min) induced by $\theta$-burst stimulation in relation to pre- $\theta$-burst values $(0 \%)$ in the absence of any drugs (open bars), or in the presence of BDNF ( $20 \mathrm{ng} / \mathrm{ml}$, filled bars) alone. Note that BDNF significantly increases LTP magnitude in hippocampal slices taken from $4(n=4)$ and 10 to I5- $(n=5)$ week-old rats, but not in slices taken from 36 to $38(n=4)$ and 70 to 80 - $(n=4)$ week-old rats. ${ }^{*} * P<0.005$ and $* P<0.05$ (paired Student's t-test) as compared with absence of BDNF in the same experiments (adjacent open column to the left).

of learning and memory associated with that brain area (Lynch, 2004), including spatial memory as assessed by the Morris water maze (Morris et al, 1982). However, LTP magnitude and memory should not be linearly related, as higher LTP in old animals does not necessarily translate into improved memory upon aging. As pointed out by Huang and Kandel (1996), who observed an age-related increase of LTP induced by a brief $1 \mathrm{~Hz}$ paired pulse stimulation, there might be forms of LTP that are negatively coupled with age-related memory loss and that may, therefore, have a negative role in memory storage. On the other hand, changes in LTP can vary in different areas of the dendritic tree as age-related decreases in basal but not apical dendrites of CA1 pyramidal neurons have been shown (Lynch et al, 2006). It is therefore possible that the now reported age-dependent increase in weak $\theta$-burstinduced LTP of apical dendrites of CA1 neurons reflects, at least in part, LTP failure in some other anatomical areas contributing to the learning and memory paradigms under assay. Clearly, memory impairment in aging is not solely related to a loss of synaptic plasticity (see also, Lynch et al, 2006).

It is known that in old rats there is no loss of hippocampal CA1 pyramidal cells (Rapp and Gallagher, 1996; Rasmussen et al, 1996), that most biophysical properties of old pyramidal cells do not differ from those in young cells, and that there is no change in spontaneous firing rates of single cells in the hippocampus of freely behaving old rats comparing with young ones (see, Barnes, 2003). With aging there is a decline in the expression of mRNA for different 
a

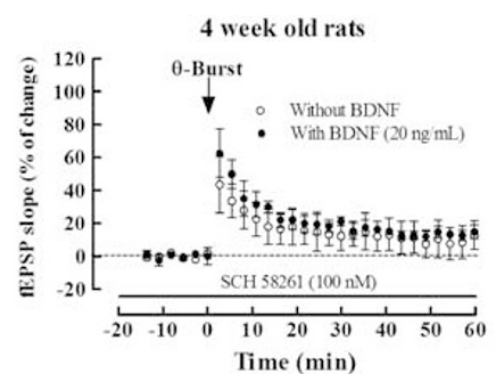

b

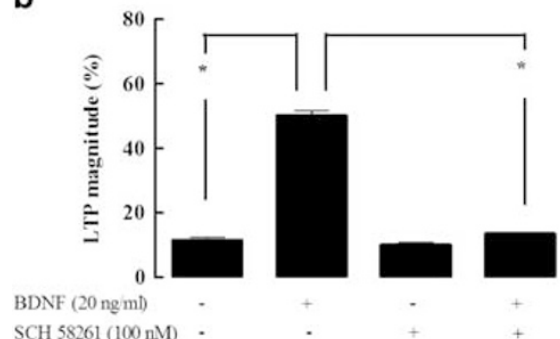

C

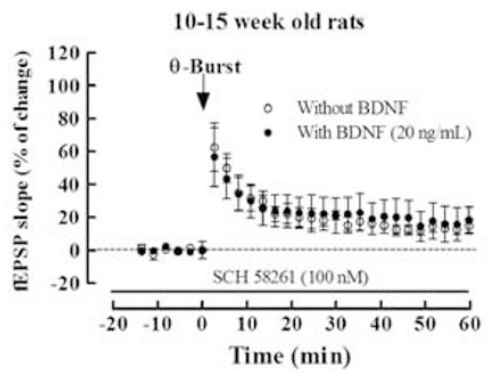

d

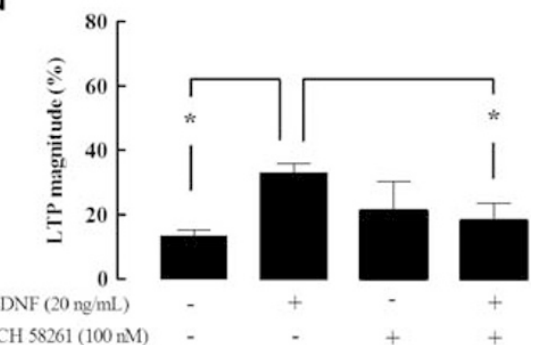

Figure 8 The antagonist of adenosine $\mathrm{A}_{2 \mathrm{~A}}$ receptors, 7-(2-phenylethyl)-5-amino-2-(2-furyl)-pyrazolo-[4,3-e]-I,2,4-triazolo[I,5-c]pyrimidine (SCH5826I), prevents the effect of brain-derived neurotrophic factor (BDNF) upon $\theta$-burst-induced long-term potentiation (LTP). Panels (a) and (c) show averaged time courses changes in field excitatory post-synaptic potential (fEPSP) slope induced by a $\theta$-burst stimulation in the absence $(O)$ or in the presence $(\mathbf{O})$ of $\operatorname{BDNF}(20 \mathrm{ng} / \mathrm{ml})$ in experiments where adenosine $A_{2 A}$ receptors $\left(A_{2 A} R\right)$ had been blocked by the selective antagonist, SCH5826I (I00 nM). The antagonist was applied 30 min before the LTP induction in the first pathway $(O)$ and remained in the bath up to the end of the experiment being therefore present during LTP induction in the first and second pathways. BDNF $(20 \mathrm{ng} / \mathrm{ml})$ was added $(0) 60$ min after the induction of LTP in the first pathway ( $O$ ) and remained up to the end of the experiment. The ordinates represents normalized fEPSP slopes, where $0 \%$ corresponds to the averaged slopes recorded for $14 \mathrm{~min}$ before $\theta$-burst stimulation: $-0.52 \pm 0.03 \mathrm{mV} / \mathrm{ms}, n=3(\mathrm{a}, \bigcirc),-0.55 \pm 0.08 \mathrm{mV} / \mathrm{ms}, n=3(\mathrm{a}, 0),-0.54 \pm 0.03 \mathrm{mV} / \mathrm{ms}, n=4(\mathrm{c}, \bigcirc)$, and $-0.63 \pm 0.07 \mathrm{mV} / \mathrm{ms}, n=4(\mathrm{c}, \mathbf{O})$, and the abscissa represents the time of recordings. Panels (b) and (d) depict the magnitude of LTP (change in the fEPSP slope at $46-60 \mathrm{~min}$ ) induced by $\theta$-burst stimulation in relation to pre- $\theta$-burst values $(0 \%)$ in the absence of any drugs (control), in the presence of BDNF $(20 \mathrm{ng} / \mathrm{ml})$ alone, in the presence of SCH 5826I (I00 nM) alone, or BDNF $(20 \mathrm{ng} / \mathrm{ml})$ together with SCH $5826 \mathrm{I}$ (I00 nM) as indicated below each column. All values are mean \pm standard error of mean (SEM). $* P<0.05$ (one-way analysis of variance (ANOVA) with the Bonferroni's correction).

NMDA receptors subunits (Magnusson, 2000; Bai et al, 2004) as well as a decrease in several NMDA subunits (Sonntag et al, 2000; Clayton et al, 2002), which might contribute to a decrease in LTP magnitude upon aging. However, LTP involves many steps besides NMDA receptors activation. We focused on the possibility that the neuromodulatory influence of BDNF on LTP could be affected by aging because the age-related increases in susceptibility to LTP induction (Kumar and Foster, 2004) are more evident when LTP is triggered by weak $\theta$-burst stimuli (Costenla et al, 1999), which favors the release of endogenous BDNF (Gartner and Staiger, 2002; Aicardi et al, 2004) as well as facilitatory actions of exogenous BDNF on LTP (Kramar et al, 2004; Fontinha et al, 2008). Our results clearly show that the BDNF scavenger, Trk-Fc, and the inhibitor of Trk phosphorylation, K252a, caused a marked decrease in LTP in slices from old but not from young rats, compatible with previous observations that early LTP in young animals is not dependent on endogenous BDNF signaling (Fontinha et al, 2008) and suggestive that upon aging there is an enhanced component of LTP that is dependent on endogenous BDNF. Interestingly, in the presence of these inhibitors of endogenous BDNF action, the magnitude of LTP in young or aged animals becomes similar. Furthermore, upon addition of exogenous BDNF, LTP magnitude in slices from young animals is markedly increased becoming comparable to that observed in slices from aged animals.

Taken together, these results strongly suggest that the age-related increases in susceptibility to LTP induction by weak $\theta$-burst stimuli involves an exacerbation of the facilitatory action of endogenous BDNF.

BDNF release can occur through two different pathways: (1) a constitutive pathway, where this molecule is spontaneously secreted or (2) a regulated pathway, where it is secreted in response to depolarization-induced transient changes in the $\mathrm{Ca}^{2+}$ concentration at release sites (see, Lessmann et al, 2003). Therefore, secretion of neurotrophins is regulated by neuronal activity being dependent on the stimulus frequency (Lim et al, 2003) and facilitated by $\theta$ burst stimulation (Gartner and Staiger, 2002; Aicardi et al, 2004). This leads to fast and highly localized changes in synaptic BDNF levels that might not reflect changes in total tissue levels of the neurotrophin. Indeed, we could not detect appreciable age-related changes in the levels of BDNF in hippocampal homogenates. Hence, the higher influence of endogenous BDNF upon LTP in aged animals might be due to an increased activity of the regulated pathway leading to an enhanced release of BDNF at synapses, accompanied by an enhanced release of adenosine, which facilitates the action of BDNF in spite of the age-dependent decline in TrkB receptors (Diógenes et al, 2007). Upon aging, there is a deficit in the regulation of calcium concentration (Landfield and Lynch, 1977), leading to increased levels of intracellular calcium in neurons (Hajieva et al, 2009). Whether this is a cause for an increase in BDNF release through the regulated pathway requires future investigation.

Whether the enhanced action of endogenous BDNF is a compensatory phenomenon physiologically aimed to 
a

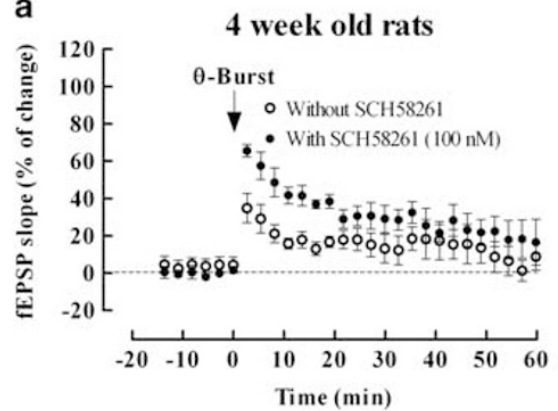

b

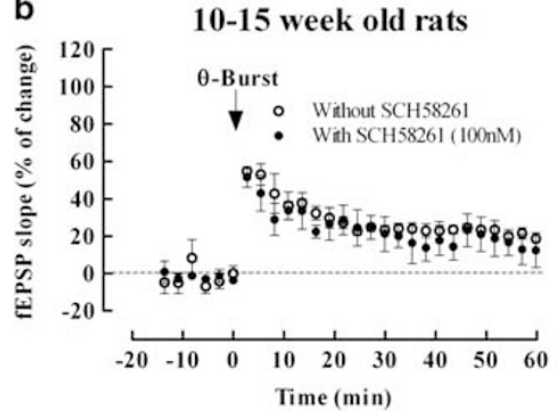

C

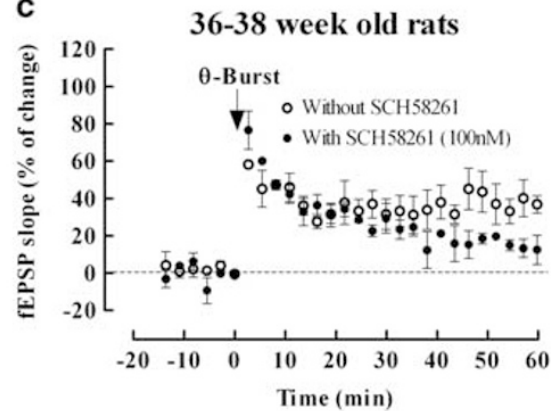

d

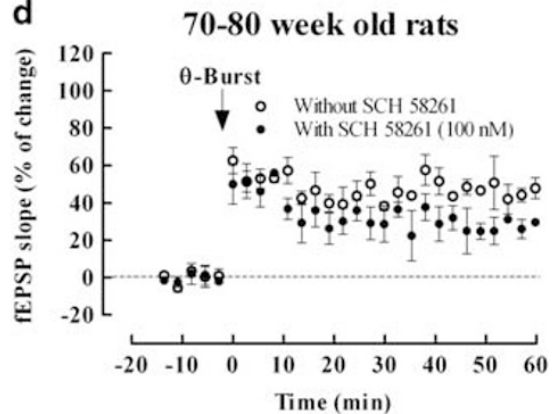

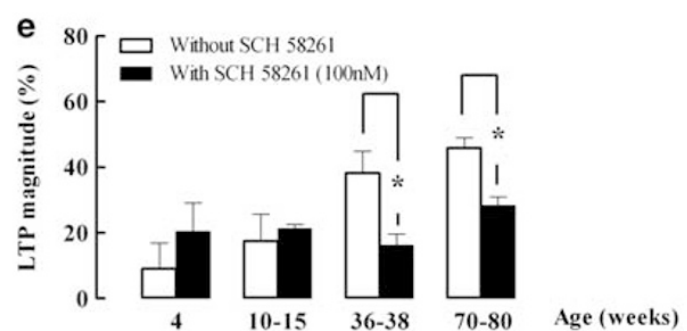

Figure 9 Age-dependent effects of 7-(2-phenylethyl)-5-amino-2-(2-furyl)-pyrazolo-[4,3-e]-1,2,4-triazolo[I,5-c]pyrimidine (SCH5826 I) (I00 nM) effect on $\theta$-burst-induced long-term potentiation (LTP). Panels (a-d) show averaged time course changes in fEPSP slope induced by the $\theta$-burst stimulation in the absence $(\mathrm{O})$ or in the presence $(\mathbf{O})$ of SCH5826I (I00 nM) in hippocampal slices taken from 4 (a), I0 to I5 (b), 36 to 38 (c), and 70 to 80 - (d) week-old rats. SCH5826 I ( $100 \mathrm{nM}$ ) was applied (O) $60 \mathrm{~min}$ after the induction of LTP in the first pathway. The ordinates represent normalized fEPSP slopes, where $0 \%$ corresponds to the averaged slopes recorded for $14 \mathrm{~min}$ before $\theta$-burst stimulation: $-0.56 \pm 0.03 \mathrm{mV} / \mathrm{ms}, n=4(a, O),-0.57 \pm 0.03 \mathrm{mV} / \mathrm{ms}, n=4$

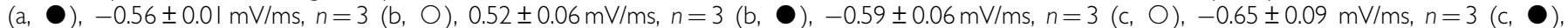
$-0.60 \pm 0.12 \mathrm{mV} / \mathrm{ms}, n=3(\mathrm{~d}, O)$, and $-0.59 \pm 0.05 \mathrm{mV} / \mathrm{ms}, n=3(\mathrm{~d}, \boldsymbol{O})$, and the abscissa represents the time of recordings. Panel (e) depicts the magnitude of LTP (change in the fEPSP slope at $46-60 \mathrm{~min}$ ) induced by $\theta$-burst stimulation in relation to pre- $\theta$-burst values $(0 \%)$ in the absence of any drugs (control) or in the presence of SCH5826I (I00 nM). Note that SCH5826I significantly decreased LTP magnitude in hippocampal slices taken from 36 to $38(n=3)$ and 70 to 80 - $(n=3)$ week-old rats, but not in slices taken from $4(n=4)$ and 10 to I5- $(n=3)$ week-old rats. All values are mean \pm standard error of mean (SEM). $* P<0.05$ (paired Student's $t$-test) as compared with absence of SCH5826I in the same experiments (adjacent open column to the left)

increase LTP and ameliorate learning and memory deficits or, in alternative, whether the enhanced action of BDNF is itself the source of an age-related increased but dysfunctional LTP remains to be established. Interestingly, in the dentate gyrus, BDNF-induced signaling and plasticity is impaired in aged rats (Gooney et al, 2004), suggesting that deficits in spatial learning could be due to deficits in BDNF/ TrkB signaling in other hippocampal areas or even in other brain regions. As discussed above, memory impairment in aging is not solely related to a loss of synaptic plasticity, and surely, spatial learning does not rely exclusively on LTP in the CA1 hippocampal area.

Synaptic plasticity is under tight control by adenosine inhibitory $A_{1}$ receptors $\left(A_{1} R\right)$ and facilitatory $A_{2 A} R$ (see eg, Costenla et al, 2010). In has been repeatedly observed that synaptic influences of $\mathrm{BDNF}$ are dependent on $\mathrm{A}_{2 \mathrm{~A}} \mathrm{R}$ receptors activation (Diógenes et al, 2004, 2007; Fontinha et al, 2008; Tebano et al, 2008; Assaife-Lopes et al, 2010), and we could confirm these observations in this work, expanding them to LTP in aged animals. Therefore, the marked LTP inhibition by a selective $\mathrm{A}_{2 \mathrm{~A}} \mathrm{R}$ antagonist in aged but not young animals may be due, at least in part, to blockade of the component of LTP that is dependent on endogenous BDNF. The density of $\mathrm{A}_{2 \mathrm{~A}} \mathrm{R}$ (Cunha et al, 1995; Lopes et al, 1999; Diógenes et $a l, 2007)$ as well as their coupling to G proteins (Lopes et al, 1999; Rebola et al, 2003; Rodrigues et al, 2008) is increased in the hippocampus of aged animals. Age-induced impact on density and function of $\mathrm{A}_{2 \mathrm{~A}} \mathrm{R}$ may underlie the preventive effects of caffeine in age-related memory impairments in rodents (Prediger et al, 2005; Costa et al, 2008), as it is mimicked by $\mathrm{A}_{2 \mathrm{~A}} \mathrm{R}$ antagonists, but not by $A_{1} R$ antagonists (Costa et al, 2008). 
Here we report that an $\mathrm{A}_{2 \mathrm{~A}} \mathrm{R}$ antagonist has a marked inhibitory effect on LTP in aged rats where endogenous BDNF actions seems to be also more evident and where impaired hippocampal-dependent memory was detected as assessed by the Morris water maze. One may therefore speculate that the positive actions of $\mathrm{A}_{2 \mathrm{~A}} \mathrm{R}$ antagonists, including caffeine, upon memory in aged subjects can, at least in part, be related to an inhibition of dysfunctional higher tonic actions of BDNF upon plasticity.

The animals used in this study were undergoing a nonpathological aging process, rather than being a model of neurodegenerative disease, such as Alzheimer's disease where total BDNF levels in the cortex and hippocampus are known to be decreased (Connor et al, 1997; Ferrer et al, 1999). Interestingly, in animal models of Alzheimer's disease, LTP is markedly decreased (Chapman et al, 1999; Oddo et al, 2003; Gureviciene et al, 2004; Trinchese et al, 2004), reinforcing the idea of an important role for a finetune regulation of synaptic BDNF levels for proper LTP and, eventually, for memory function. In what concerns influence of BDNF upon LTP, it should be stressed that not only the amount, but also the timing and pattern of BDNF release are crucial for shaping the actions of BDNF at synapses (Ji et al, 2010).

In conclusion, we show for the first time that, in a situation of non-pathological aging, the actions of BDNF are increased upon synaptic plasticity in aged animals. As no changes in total hippocampal levels of this neurotrophin where detected, this enhanced effects are probably due to an increased tonic action of BDNF upon high-frequency neuronal firing.

\section{ACKNOWLEDGEMENTS}

The work was supported by Fundação para a Ciência e Tecnologia, Fundação Calouste Gulbenkian and EU (COST B-30 concerted action). André Jerónimo-Santos and Vasco Sousa were supported by Fundação para a Ciência e Tecnologia (AJS: SFRH/BD/62828/2009; VCS: SFRH/BD/ 21359/2005, PhD fellowships). We thank Regeneron for the gift of brain-derived neurotrophic factor and WW Andersen (University of Bristol, Bristol, UK) for the gift of the data analysis (LTP) program. We also acknowledge Alexandre de Mendonça and Antonina Pereira for scientific discussions. The animal housing facilities of the Institute of Physiology of the Faculty of Medicine of the University of Lisbon are also acknowledged.

\section{DISCLOSURE}

All authors state the absence of actual or potential conflicts of interest including any financial, personal, or other relationships with other people or organizations within 3 years of beginning the work submitted that could inappropriately influence (bias) their work. The authors' institution has no contracts relating to this research through which it or any other organization may stand to gain financially now or in the future. None of the authors or their institutions has any other agreements that could be seen as involving a financial interest in this work.

\section{REFERENCES}

Aicardi G, Argilli E, Cappello S, Santi S, Riccio M, Thoenen H et al (2004). Induction of long-term potentiation and depression is reflected by corresponding changes in secretion of endogenous brain-derived neurotrophic factor. Proc Natl Acad Sci USA 101: 15788-15792.

Anderson WW, Collingridge GL (2001). The LTP program: a data acquisition program for on-line analysis of long-term potentiation and other synaptic events. J Neurosci Methods 108: 71-83.

Assaife-Lopes N, Sousa VC, Pereira DB, Ribeiro JA, Chao MV, Sebastiao AM (2010). Activation of adenosine A2A receptors induces TrkB translocation and increases BDNF-mediated phospho-TrkB localization in lipid rafts: implications for neuromodulation. J Neurosci 30: 8468-8480.

Auffret A, Gautheron V, Mattson MP, Mariani J, Rovira C (2010). Progressive age-related impairment of the late long-term potentiation in Alzheimer's disease presenilin-1 mutant knockin mice. J Alzheimers Dis 19: 1021-1033.

Bai L, Hof PR, Standaert DG, Xing Y, Nelson SE, Young AB et al (2004). Changes in the expression of the NR2B subunit during aging in macaque monkeys. Neurobiol Aging 25: 201-208.

Balkowiec A, Katz DM (2002). Cellular mechanisms regulating activity-dependent release of native brain-derived neurotrophic factor from hippocampal neurons. J Neurosci 22: 10399-10407.

Barnes CA (1979). Memory deficits associated with senescence: a neurophysiological and behavioral study in the rat. J Comp Physiol Psychol 93: 74-104.

Barnes CA (2003). Long-term potentiation and the ageing brain. Philos Trans R Soc Lond Ser B 358: 765-772.

Billard JM, Lamour Y, Dutar P (1995). Decreased monosynaptic GABAB-mediated inhibitory postsynaptic potentials in hippocampal CA1 pyramidal cells in the aged rat: pharmacological characterization and possible mechanisms. J Neurophysiol 74: 539-546.

Bradford MM (1976). A rapid and sensitive method for the quantitation of microgram quantities of protein utilizing the principle of protein-dye binding. Anal Biochem 72: 248-254.

Chapman PF, White GL, Jones MW, Cooper-Blacketer D, Marshall VJ, Irizarry $M$ et al (1999). Impaired synaptic plasticity and learning in aged amyloid precursor protein transgenic mice. Nat Neurosci 2: 271-276.

Clayton DA, Mesches MH, Alvarez E, Bickford PC, Browning MD (2002). A hippocampal NR2B deficit can mimic age-related changes in long-term potentiation and spatial learning in the Fischer 344 rat. J Neurosci 22: 3628-3637.

Connor B, Young D, Yan Q, Faull RL, Synek B, Dragunow M (1997). Brain-derived neurotrophic factor is reduced in Alzheimer's disease. Brain Res Mol Brain Res 49: 71-81.

Costa MS, Botton PH, Mioranzza S, Souza DO, Porciuncula LO (2008). Caffeine prevents age-associated recognition memory decline and changes brain-derived neurotrophic factor and tyrosine kinase receptor (TrkB) content in mice. Neuroscience 153: 1071-1078.

Costenla AR, de Mendonca A, Ribeiro JA (1999). Adenosine modulates synaptic plasticity in hippocampal slices from aged rats. Brain Res 851: 228-234.

Costenla AR, Cunha RA, de Mendonça A (2010). Caffeine, adenosine receptors and synaptic plasticity. J Alzheimer Dis 20(Suppl 1): S25-S34.

Cunha RA, Constantino MC, Sebastião AM, Ribeiro JA (1995). Modification of A1 and A2a adenosine receptor binding in aged striatum, hippocampus and cortex of the rat. NeuroReport 6: 1583-1588.

Diógenes MJ, Assaife-Lopes N, Pinto-Duarte A, Ribeiro JA, Sebastiao AM (2007). Influence of age on BDNF modulation of 
hippocampal synaptic transmission: interplay with adenosine A2A receptors. Hippocampus 17: 577-585.

Diógenes MJ, Fernandes CC, Sebastiao AM, Ribeiro JA (2004). Activation of adenosine A2A receptor facilitates brain-derived neurotrophic factor modulation of synaptic transmission in hippocampal slices. J Neurosci 24: 2905-2913.

Ferrer I, Marin C, Rey MJ, Ribalta T, Goutan E, Blanco R et al (1999). BDNF and full-length and truncated TrkB expression in Alzheimer disease. Implications in therapeutic strategies. J Neuropathol Exp Neurol 58: 729-739.

Figurov A, Pozzo-Miller LD, Olafsson P, Wang T, Lu B (1996). Regulation of synaptic responses to high-frequency stimulation and LTP by neurotrophins in the hippocampus. Nature 381: 706-709.

Fontinha BM, Diógenes MJ, Ribeiro JA, Sebastiao AM (2008). Enhancement of long-term potentiation by brain-derived neurotrophic factor requires adenosine A2A receptor activation by endogenous adenosine. Neuropharmacology 54: 924-933.

Gartner A, Staiger V (2002). Neurotrophin secretion from hippocampal neurons evoked by long-term-potentiation-inducing electrical stimulation patterns. Proc Natl Acad Sci USA 99: 6386-6391.

Gooney M, Messaoudi E, Maher FO, Bramham CR, Lynch MA (2004). BDNF-induced LTP in dentate gyrus is impaired with age: analysis of changes in cell signaling events. Neurobiol Aging 25: $1323-1331$.

Gureviciene I, Ikonen S, Gurevicius K, Sarkaki A, van Groen T, Pussinen $\mathrm{R}$ et al (2004). Normal induction but accelerated decay of LTP in APP+PS1 transgenic mice. Neurobiol Dis 15: 188-195.

Hajieva P, Kuhlmann C, Luhmann HJ, Behl C (2009). Impaired calcium homeostasis in aged hippocampal neurons. Neurosci Lett 451: 119-123.

Havenaar R, Meijer JC, Morton DB, Ritskes-Hoitinga Zwart P (1993). Principles of Laboratory Animal Science. A Contribution to the Humane Use and Care of Animals and to the quality of Experimental Results: Biology and Husbandry of Laboratory Animals. Elsevier: New York.

Huang YY, Kandel ER (1996). Age-related enhancement of a protein synthesis-dependent late phase of LTP induced by low frequency paired-pulse stimulation in hippocampus. Learn Mem 13: $298-306$.

Ji Y, Lu Y, Yang F, Shen W, Tang TT, Feng L et al (2010). Acute and gradual increases in BDNF concentration elicit distinct signaling and functions in neurons. Nat Neurosci 13: 302-309.

Kang H, Schuman EM (1995). Long-lasting neurotrophin-induced enhancement of synaptic transmission in the adult hippocampus. Science 267: 1658-1662.

Knusel B, Hefti F (1992). K-252 compounds: modulators of neurotrophin signal transduction. J Neurochem 59: 1987-1996.

Korte M, Carroll P, Wolf E, Brem G, Thoenen H, Bonhoeffer T (1995). Hippocampal long-term potentiation is impaired in mice lacking brain-derived neurotrophic factor. Proc Natl Acad Sci USA 92: 8856-8860.

Korte M, Griesbeck O, Gravel C, Carroll P, Staiger V, Thoenen H et al (1996). Virus-mediated gene transfer into hippocampal CA1 region restores long-term potentiation in brain-derived neurotrophic factor mutant mice. Proc Natl Acad Sci USA 93: 12547-12552.

Kramar EA, Lin B, Lin CY, Arai AC, Gall CM, Lynch G (2004). A novel mechanism for the facilitation of theta-induced long-term potentiation by brain-derived neurotrophic factor. J Neurosci 24 : 5151-5161.

Kumar A, Foster TC (2004). Enhanced long-term potentiation during aging is masked by processes involving intracellular calcium stores. J Neurophysiol 91: 2437-2444.

Kumar A, Thinschmidt JS, Foster TC, King MA (2007). Aging effects on the limits and stability of long-term synaptic potentiation and depression in rat hippocampal area CA1. J Neurophysiol 98: 594-601.

Landfield PW, Lynch G (1977). Impaired monosynaptic potentiation in in vitro hippocampal slices from aged, memory-deficient rats. J Gerontol 32: 523-533.

Lessmann V, Gottmann K, Malcangio M (2003). Neurotrophin secretion: current facts and future prospects. Prog Neurobiol 69: 341-374.

Lim KC, Lim ST, Federoff HJ (2003). Neurotrophin secretory pathways and synaptic plasticity. Neurobiol Aging 24: 1135-1145.

Lopes LV, Cunha RA, Ribeiro JA (1999). Increase in the number, G protein coupling, and efficiency of facilitatory adenosine A2A receptors in the limbic cortex, but not striatum, of aged rats. J Neurochem 73: 1733-1738.

Lynch MA (2004). Long-term potentiation and memory. Physiol Rev 84: 87-136.

Lynch G, Rex CS, Gall CM (2006). Synaptic plasticity in early aging. Ageing Res Rev 5: 255-280.

Magnusson KR (2000). Declines in mRNA expression of different subunits may account for differential effects of aging on agonist and antagonist binding to the NMDA receptor. J Neurosci 20: 1666-1674.

Minichiello L, Calella AM, Medina DL, Bonhoeffer T, Klein R, Korte M (2002). Mechanism of TrkB-mediated hippocampal long-term potentiation. Neuron 36: 121-137.

Morris RG, Garrud P, Rawlins JN, O’Keefe J (1982). Place navigation impaired in rats with hippocampal lesions. Nature 297: 681-683.

Oddo S, Caccamo A, Shepherd JD, Murphy MP, Golde TE, Kayed R et al (2003). Triple-transgenic model of Alzheimer's disease with plaques and tangles: intracellular Abeta and synaptic dysfunction. Neuron 39: 409-421.

Patterson SL, Abel T, Deuel TA, Martin KC, Rose JC, Kandel ER (1996). Recombinant BDNF rescues deficits in basal synaptic transmission and hippocampal LTP in BDNF knockout mice. Neuron 16: 1137-1145.

Prediger RD, Batista LC, Takahashi RN (2005). Caffeine reverses age-related deficits in olfactory discrimination and social recognition memory in rats. Involvement of adenosine A1 and A2A receptors. Neurobiol Aging 26: 957-964.

Rapp PR, Gallagher M (1996). Preserved neuron number in the hippocampus of aged rats with spatial learning deficits. Proc Natl Acad Sci USA 93: 9926-9930.

Rasmussen T, Schliemann T, Sorensen JC, Zimmer J, West MJ (1996). Memory impaired aged rats: no loss of principal hippocampal and subicular neurons. Neurobiol Aging 17: 143-147.

Rebola N, Sebastiao AM, de Mendonca A, Oliveira CR, Ribeiro JA, Cunha RA (2003). Enhanced adenosine A2A receptor facilitation of synaptic transmission in the hippocampus of aged rats. J Neurophysiol 90: 1295-1303.

Rex CS, Kramar EA, Colgin LL, Lin B, Gall CM, Lynch G (2005). Long-term potentiation is impaired in middle-aged rats: regional specificity and reversal by adenosine receptor antagonists. J Neurosci 25: 5956-5966.

Rodrigues RJ, Canas PM, Lopes LV, Oliveira CR, Cunha RA (2008). Modification of adenosine modulation of acetylcholine release in the hippocampus of aged rats. Neurobiol Aging 29: 1597-1601.

Sebastiao AM, Ribeiro JA (2009). Triggering neurotrophic factor actions through adenosine $\mathrm{A} 2 \mathrm{~A}$ receptor activation: implications for neuroprotection. Br J Pharmacol 158: 15-22.

Simmons DA, Rex CS, Palmer L, Pandyarajan V, Fedulov V, Gall $\mathrm{CM}$ et al (2009). Up-regulating BDNF with an ampakine rescues synaptic plasticity and memory in Huntington's disease knockin mice. Proc Natl Acad Sci USA 106: 4906-4911.

Sonntag WE, Bennett SA, Khan AS, Thornton PL, Xu X, Ingram RL et al (2000). Age and insulin-like growth factor-1 modulate 
Enhanced LTP in aging is dependent on endogenous BDNF

MJ Diógenes et al

$N$-methyl-D-aspartate receptor subtype expression in rats. Brain Res Bull 51: 331-338.

Tebano MT, Martire A, Potenza RL, Grò C, Pepponi R, Armida M et al (2008). Adenosine $\mathrm{A}(2 \mathrm{~A})$ receptors are required for normal BDNF levels and BDNF-induced potentiation of synaptic transmission in the mouse hippocampus. J Neurochem 104: 279-286.

Trinchese F, Liu S, Battaglia F, Walter S, Mathews PM, Arancio O (2004). Progressive age-related development of Alzheimer-like pathology in APP/PS1 mice. Ann Neurol 55: 801-814.

Tsvyetlynska NA, Hill RH, Grillner S et al (2005). Role of AMPA receptor desensitization and the side effects of a DMSO vehicle on reticulospinal EPSPs and locomotor activity. J Neurophysiol 94: 3951-3960.

Xu B, Gottschalk W, Chow A, Wilson RI, Schnell E, Zang K et al (2000). The role of brain-derived neurotrophic factor receptors in the mature hippocampus: modulation of long-term potentiation through a presynaptic mechanism involving TrkB. J Neurosci 20: 6888-6897.

Zocchi C, Ongini E, Conti A, Monopoli A, Negretti A, Baraldi PG et al (1996). The non-xanthine heterocyclic compound SCH 58261 is a new potent and selective A2a adenosine receptor antagonist. J Pharmacol Exp Ther 276: 398-404. 